This is the peer reviewed version of the following article: Baskerville, R. and Myers, M. 2015. Design ethnography in information systems. Information Systems Journal. 25 (1): pp. 23-45, which has been published in final form at http://doi.org/10.1111/isj.12055. This article may be used for noncommercial purposes in accordance with Wiley Terms and Conditions for Self-Archiving at http://olabout.wiley.com/WileyCDA/Section/id-820227.html\#terms 


\title{
Design Ethnography in Information Systems
}

\author{
Richard Baskerville \\ Georgia State University \\ Curtin University \\ Michael Myers \\ University of Auckland
}

\section{Abstract}

Until recently most ethnographic research in information systems has been based on the traditional anthropological model of ethnography. In this traditional model of ethnography one of the most important data gathering techniques is participant observation. The ethnographer observes and participates, but does not actively seek to change the situation. In recent years, however, a new type of ethnographic research has emerged - one that can be called design ethnography. Design ethnography is where the researcher goes beyond observation and actively engages with people in the field. Our view is that design ethnography has much potential for research in information systems. It is a new form of engaged scholarship that bridges the gap between ethnographic research and design science research.

\section{Introduction}

Research methods in information systems and other fields are continuously evolving. In information systems this evolution is driven by both innovative methodological improvements and the changing landscape of information systems technologies and practices. One noticeable shift in recent years has been toward more engagement between research and practice. This increase in engagement arises from advances in both action research and design science research.

Design science research methodology seeks to bridge research and practice by embracing both a rigor cycle and a relevance cycle. It centers a build-and-evaluate cycle that exchanges inputs and outputs with a knowledge base (the rigor cycle) and with real world artifact application (the relevance cycle) (Hevner, 2007; Hevner et al., 2004). In the past few decades, there have been considerable developments in the use of design theory (Gregor and Jones, 2007; Walls et al., 1992), the nature of design artifacts (March and Smith, 1995; Orlikowski and lacono, 2001) and design science methodologies (Peffers et al., 2008; Vaishnavi and Kuechler, 2007).

Action research also seeks to bridge research and practice by enrolling broader participation in social organizational research that aims at both practical and knowledge goals (Rapoport, 1970; Susman and Evered, 1978). It centers a cycle aimed at learnings outcomes that results from theory-driven practical action in a problematic work setting (Davison et al., 2004).

These two approaches are cornerstones of Van de Ven's proposal toward a more engaged form of scholarship in the world of business academia (Van de Ven, 2007). Action research and design science research share similar iterative approaches to complex problem settings and promote intervention as a means of studying these kinds of settings. Both can be anchored to pragmatist philosophy (Baskerville and Myers, 2004; Goldkuhl, 2012). Sein et al. (2011) have merged the two into a 
single methodology called action design research that they argue is particularly relevant for information systems research.

This increasing interest in engagement is not just germane to the field of information systems, but has grown in importance in other business disciplines as well (Starkey et al., 2009; Thorpe and Rawlinson, 2014). Many researchers in business have discovered that engagement is not always an option. As important problems arise (or crises unfold) in the setting, research subjects may implore the researcher for advice and help. Such importunate requests may arise particularly if the subjects perceive the researcher to be an expert in the area. In our own experience we have found that our doctoral students (as well as ourselves) are often perceived by people in the field to be experts in information systems. Is it appropriate for the ethnographic researcher to simply ignore such requests for help? We do not think so.

However, a researcher who becomes drawn into action in the research setting might find it difficult to reconcile this active engagement with current descriptions of how ethnographic research is supposed to be conducted. Researchers may feel that they have made a wreck of their research design as their participant observation turns into giving advice, and their research design starts to look more like action research or design science than traditional ethnography. This problem is particularly difficult for ethnographic researchers because ethnographers are supposed to learn from the people in the field. The ethnographer "becomes a student of other people's culture" (Myers, 2013, p. 94). A lapse into active engagement might be seen as just the opposite - instead of learning, the researcher becomes a teacher or advisor.

We suggest that recent developments in anthropology may offer a solution. A form of ethnography is emerging that allows and even encourages the active engagement of the ethnographer with people in the field. This new type of ethnographic research is what can be called design ethnography. Design ethnography is an important advance because it enables both the IS researcher and the people in the field to learn from each other. Our view is that design ethnography has much potential for research in information systems.

The purpose of this paper is to introduce these recent design ethnography developments arising from anthropology, and to adapt these developments for specific application in information systems research. The paper is organized as follows. We will first of all discuss how ethnographic research has traditionally been described in the IS research literature. We then discuss the relationship between ethnography and design focusing in particular on design ethnography. This is followed by our suggested criteria for the evaluation of design ethnography. The final section is the discussion and conclusions.

\section{Review of Ethnography in IS}

In this section we briefly review how ethnography has been used in IS research. In describing the contribution of the ethnographic method to IS research, Harvey and Myers (1995) say that ethnographic research is "well suited to providing information systems researchers with rich insights into the human, social and organizational aspects of information systems development and application" (Harvey and Myers, 1995, p. 22). Myers (1999) says that ethnographic research is one of the most in-depth research methods possible because it enables a researcher to see what people are doing as well as what they say they are doing. The ethnographer seeks to place the phenomena studied in its social and cultural context (Avison and Myers, 1997).

Ethnographic research was first used by IS scholars to study the relationship between information systems and changing nature of work and practice (Suchman, 1987; Wynn, 1991; Zuboff, 1988). For example, Zuboff (1988) conducted in-depth ethnographic fieldwork immersing herself in the 
workplace of a company. She suggested that information technology could be used in two different ways: to automate work or to 'informate' work. She pointed out that the informating potential of IT could enable more stimulating, challenging jobs, with greater employee satisfaction.

This subject of IT and work is still an important theme today, but over the past two decades IS scholars have used ethnography to study the information systems development and implementation (Lee and Myers, 2004; Myers and Young, 1997), information systems management (Davies, 1991; Davies and Nielsen, 1992), the relationship between information systems and organizations (Orlikowski, 1991; Orlikowski and Robey, 1991), and the culture of an information economy (Trauth, 2000).

For example, Orlikowski (1991) conducted her fieldwork in a large multinational software firm. She describes this firm as a "quintessential "knowledge-based' firm," where all employees are referred to as "professionals." It is our expectation that professionals have significant discretion over their own work. However, Orlikowski found that information technology reinforced established forms of organizing and enabled the existing forms of control to be intensified and fused. She says that when information technology mediates work processes, it can enable a disciplinary matrix of knowledge and power.

Recent ethnographic work in IS shows considerable variety in the topics chosen. For example, Campbell et al. (2009) used ethnographic research to study conflict in an online financial community. They suggest that conflict, in contrast to trust and social cohesion, can provide an alternative set of unifying principles and rationales for understanding social interaction. Kvasny et al. (2009) used ethnographic research to explore how the intersection of gender, race, and class identities shape the experiences of black female IT workers and learners in the USA. Their study provides a nuanced understanding of social exclusion and varied emancipatory practices amongst the IT workforce. Ribes and Finholt (2009) used ethnographic research to capture participants' formulation of problems in their daily work of developing four US e-infrastructure projects for the earth and environmental sciences. They suggest the concept of the "long now" as an organizing principle for analyzing the work of planning and sustaining infrastructure. The concept of the long now encourages a consideration of how today's planning will effect tomorrow's technologies through the practical work of designing, (re)constructing, and maintaining these systems. Leonardi $(2011,2013)$ used ethnographic research to study a major automaker in the United States. Based on this work he illustrated the use of the imbrication metaphor to suggest how a human agency approach to technology can usefully incorporate notions of material agency into its explanations of organizational change. Ravishankar et al. (2013) used ethnographic research in a study of IT offshoring to explore how Indian IT services vendor organizations experience and respond to power asymmetries in their relationships with Western client organizations. They suggest that concepts from postcolonial theory help to understand and explain the experiences and responses of one Indian vendor.

As well as variety in the topics chosen, IS researchers have used various kinds of ethnographic research. Some of those that have been used by IS scholars include confessional ethnography (Schultze, 2000), critical ethnography (Myers, 1997), postmodern ethnography (Harvey, 1997) and netnography (Campbell et al., 2009). Schultze's (2000) article is a good example of confessional ethnography. She studied the informing practices of knowledge workers. The confessional genre requires the ethnographer to give a self-revealing and self- reflexive account of the research process. In her case she was able to draw on her own experiences as an ethnographic researcher to draw readers into the text. She identified parallels between her own informing practices and those of the knowledge workers she studied with the intent of challenging readers to examine their own informing practices. As an example of critical ethnography, Myers and Young (1997) studied an IS development project at a city hospital. They looked at how power and the hidden agendas of management, along with other "taken for granted" aspects of social reality, can be deeply embedded within IS development process. Using 
Habermas' model of societal development, their field study revealed how the information system contained within itself the hidden agendas of management, and more broadly of the New Zealand Government. Germonprez and Hovorka (2013) used netnography to study member engagement within a digitally enabled social network. Netnography is a form of ethnography that involves the ethnographer conducting their fieldwork online. In Germonprez and Hovorka's case, they studied an online community by participating in and observing their social interactions via web sites, blogs and discussion forums. Their research demonstrates the potential of using netnography to study digitally enabled social networks and sheds light on the importance of maintaining user engagement in these networks.

Our review of the IS research literature reveals that various kinds of ethnography have been used to study a variety of topics. Many important contributions have been made, including those of a theoretical nature. However, almost all ethnographic research in IS so far has been based on the traditional anthropological model of ethnography. The traditional model is where the ethnographer observes and participates, but does not actively seek to change the situation. Participant observation is regarded as one of the defining features of all kinds of ethnographic research (Myers, 1999). The ethnographer observes and participates, but does not actively seek to change the situation (at least not deliberately). Although netnography is perhaps the most recent methodological innovation with respect to ethnography, it still relies primarily on the description of social and cultural activities within an online community. There is no active intervention as such. Hence we conclude that ethnographic research as currently described in the IS research literature does not include any active intervention on the part of the researcher.

\section{The relationship between ethnography and design}

In this section we consider how ethnography has come to be associated with design. Although most ethnographers in IS have not been involved in any active intervention, there are examples where ethnographers have been, as Hughes et al. put it, (1992) "faltering from ethnography to design." In other words, the ethnographers have started to actively engage with the people in the field, but tended to do so in a tentative manner.

In the field of information systems, design is a rich, multifaceted concept. It is all at once a product, a process, an intention, a practice, and a service that is alive with ethnographically attractive aspects such as problem-solving, planning, communication, experience and value (McKay et al., 2012). We suggest there are three ways in which ethnography can be conceptualized as being engaged with design. The first two ways are somewhat tentative uses of ethnography with design and are forerunners of the third.

The first way is where ethnographic research is used to aid in the design of an artifact. This is ethnography for design (E4D) and involves using ethnographic techniques to tease out what the design goals or user requirements might be from the minds and behavior of the people concerned. This is the most common way in which ethnography has been associated with design in IS research.

The second way treats the design process itself as a subject of ethnographic analysis. This is ethnography to study design (E2D) and focuses on how designers go about their work. There are examples of this in the IS research literature, although this way of using ethnography is less common than the first.

The third way builds on the previous two, but to our knowledge has not been used in IS research as yet. This third way is one in which the researcher is no longer so tentative, but rather actively engages with the people in the field. This third way is what we call design ethnography (DE). In this case the ethnographic research techniques are fully integrated with design science techniques. For example, as 
well as ethnographic techniques being used to find out user requirements, the design task itself can be used as a vehicle to better understand the everyday lives of the people. Our view is that it is this third way that has much potential for research in information systems. Building on the first two forms, it is a new method of engaged scholarship that bridges the gap between ethnographic research and design science research. We now discuss each of these three ways in more detail below.

The First Way: Ethnography for Design (E4D)

Ethnography for design (E4D) arose in the 1970s when designers learned how useful ethnographic methods and data were for understanding users and consumers (Otto and Smith, 2013). In this case the ethnography "focuses on the broad patterns of everyday life that are important and relevant specifically for the conception, design, and development of new products and services" (Salvador et al., 1999, p.36). Ethnography for design is aimed at a deeper description of the users or consumers of the artifact being designed. It facilitates better designs by trying to obtain a deeper understanding of the future users of the proposed product. It presupposes that this better understanding will lead to more ideal features being incorporated into the design. By learning about the ideas, beliefs, values and behaviors of users and consumers, designers can translate these into useful ideas for design, engineering, and marketing. In IS this form of ethnography was suggested as a means whereby multiple perspectives can be incorporated in information systems design (Holzblatt and Beyer, 1993; Star, 1995).

The value of E4D was recognized early in design studies because deep insights into consumer behavior have great commercial (practical) value. Denny (2002) describes three important assumptions that pervade this form of design ethnography. First, because knowledge is concrete and layered, strong tools are needed to discover unmet needs. Learning what people need may involve piercing jargon, slogans or contextual expressions. Second, the functional should be separate from the symbolic. The functional properties of an artifact are easy to measure, but ethnography is needed to explore the symbolic properties of an artifact. The meaning that people attach to a product might not be immediately obvious. Third, what people do is often different from what they say. Ethnography for design observes what people do, not just what they say they do. Ethnography for design seeks to understand how people live (Salvador et al., 1999).

Ethnography for design (E4D) is the first way in which ethnography has come to be associated with design. It represents the use of ethnography simply as a means to improve designs. Where this is the only purpose of the ethnography, interesting knowledge about the behaviors, mores, beliefs, or values that the ethnographers uncovered beyond that relevant for the design purposes is a waste output of the ethnography. Wasson describes this limited purpose as a "pale shadow of ethnography", a "thinned out and reduced" notion that sometimes amounts to little more than a "designer with a video camera" (Wasson, 2002, p.87). E4D could also be criticized because it has the same advocacy orientation as participatory action research in that the ethnographer easily becomes an advocate in their own studies, for example advocating designs that promote economically or politically marginalized groups (Sanjek, 2004).

Nevertheless there are cases where the ethnographic data arising from E4D has been usefully applied for both its design and its knowledge value. Because there is a long history of E4D, there are many examples in the literature. Lucy Suchman pioneered E4D in software design at the Xerox Palo Alto Research Center (PARC) (Wasson, 2000). A few of those providing detailed accounts of E4D techniques include the use of E4D in instructional design (Barab et al., 2004), in museum design (Hatala and Wakkary, 2005), and in software development (Macaulay et al., 2009). 


\section{The Second Way: Ethnography to study Design (E2D)}

While it is probably more correct to regard this second way of ethnography (E2D) as the study of designers, much of the literature describes the subject in terms of the design activity. Design, as a context for human activity, is a complex activity that produces complex outcomes, often in unique situations. Design itself is a "prospective action, that is actively reflecting within a present moment on future action and contingency" (Wakkary, 2005, p. 66). Such behavioral characteristics are shared with other similar prescriptive activities such as planning and navigating. Some claim that the use of ethnographic techniques to study design "as a modern phenomenon is still in its infancy" (Otto and Smith, 2013, p. 2).

However, there is a long tradition of using E2D in information systems and human-computer interaction. Pioneers such as Bjerknes, Ehn and Kyng made an important contribution to participatory design in Scandinavia (Bjerknes et al., 1987). In the field of human-computer interaction, ethnographic research has been used to better understand designers and the design process (Ball and Ormerod, 2000; Thomas, 2003).

Participative design workshops yield some of the best examples of E2D available today. Although the ethnographic focus is often on the user/consumer participants, the ethnography cannot help but include the designer participants as well (e.g., Wakkary, 2005).

\section{The Third Way: Design Ethnography (DE)}

In our view, the first two ways of ethnography being associated with design have paved the way for the third. Building on the first two, the third way is one where the ethnographer is actively immersed and engaged in a setting where people are either designing artifacts, producing artifacts, or introducing artifacts into a social and cultural context. Although some call this third way design anthropology (Gunn and Donovan, 2013; Gunn et al., 2013), we prefer the term design ethnography (DE) to reflect the fact that in information systems we are primarily information scholars, not anthropologists, and for us ethnography (including DE) is a research method.

DE builds forward from E4D and E2D. Ethnographer-designers will want ethnographic forms of data on which to base their designs (E4D); and like E2D, the ethnographer-designer will be immersed in practical acts of designing, which, along with science, technology, and art, has become an important domain of cultural production (Berglund, 2014). Ethnographer-designers cannot fail to include the social and cultural aspects of design itself within their studies. But there are several important differences that separate this third way of coupling design and ethnography from previous ways. There are differences in practices, temporality, and materiality.

\section{Practices are different}

The practices of design ethnography are generative as well as descriptive. DE transcends the present dependence on ethnography as a descriptive practice. These practices extend to learning about a culture or society through intervention and synthesis rather than just analysis. The design ethnographer uses "designerly" ways of thinking and acting to improvise: introducing concepts and artifacts into the study setting (Otto and Smith, 2013, p.13). By engaging in design, the researcher opens horizons beyond just cultural critique, and explores by creating correspondence with the research setting. Correspondence is a concept that incorporates a researcher's engagement in forms of reciprocity and counterpoint with the study setting: akin to a cultural or social dance in which the subjects and the researchers co-design their steps in ways that correspond with one another (Gatt and Ingold, 2013)

\section{Temporality is different}

DE operates according to a different time frame than might be typical in most ethnographic studies. Most obvious is the future orientation of the research process. The basis in design means the work has 
a more prescriptive element, similar to design science research. However, in design ethnography the future-oriented knowledge includes an expectation that culture or society will continue to change in expected (and sometimes unexpected) ways (Otto and Smith, 2013).

In design ethnography, shorter time frames are more common. In contrast to ethnographies that involve long-term fieldwork in a single culture or society, design anthropology occurs in a series of short, interventional field studies that may be set in different cultures or societies. However, the openendedness of design behaviors is preserved. Design, as a human behavior, might have episodic elements, but it is still a continuous aspect of a person. Design is not restricted to an act of designing-athing, but is an ongoing human trait of designing. While traditional ethnography is often delivering highly idiographic knowledge, design ethnography uses this knowledge as a basis for reflecting across cultural boundaries. This regard for the broader scope of the knowledge also emanates from the early use of ethnography in design studies, where the desired knowledge was motivated in a product-market context. Such ethnography was meant to deliver quasi-universal knowledge about the market into which a product would be delivered.

This more lenient approach to temporality means that the concept of correspondence is, like design, also open ended. Design ethnographers seek to develop correspondence that is expected to continue into the future (Gatt and Ingold, 2013).

\section{Materiality is different}

Unlike most traditional ethnographies, the material dimension becomes central in design anthropology. There are material practices involved in design conceptualization, visualization, prototyping, and performance (Otto and Smith, 2013). Material differences in design may reflect social and cultural values. For example, Ewart (2013) became engaged in designing bridges in a remote area of Borneo. Two bridge designs were developed: one was a suspension bridge using wire rope and concrete anchors, and the other was a hanging bridge using bamboo and rattan. The first was designed using engineering diagrams and symbols. The second was designed in an emergent way, unwritten and subjected to change according to the geography and the materials at hand. The first was designed for permanence, the second for easy reconstruction after any destructive flood. Both were designed, both were constructed, but the materiality in the two designs yielded important knowledge about values in the differing cultures represented (such as the value of natural materials and the likelihood of natural events).

We can summarize the nature of design ethnography by saying it is a form of ethnographic research that is more than just immersed, and more than just participative, but one in which the researcher is actively intervening in changing the subject area-the context-in which the researcher is researching. The researcher is actively engaged with others in a future-oriented way: designing, creating, innovating, and improvising artifacts that may affect the cultural and social values under study.

\section{How to do Design Ethnography}

Before proceeding to the details of a methodology for design anthropology, we should briefly review the concept of ethnographic tools or toolkits. This concept draws attention to a very broad landscape of techniques and technologies that ethnographers employ in gleaning insights from their research contexts, particularly regarding the problematic task of capturing social and cultural values. Many of these tools have themselves been borrowed from other disciplines. Appendix 1 defines and briefly explains the most common ethnographic tools, although it is beyond the scope of this paper to provide a comprehensive survey of all ethnographic tools. Three different categories of tools seem to be relevant for DE. 
Ethnographic toolkit (E4D). Any of the traditional tools used in ethnography and especially ethnography for design might be appropriate when conducting DE. Examples include interviewing, fieldwork, immersion, conversation analysis, genealogies, social mapping, demography, photography, documentary film making and videos, archival research etc. (Salvador et al., 1999, p.36).

Ethnography to design toolkit (E2D). Where the subject of the ethnography includes design itself, additional tools are commonly found. For example, design workshops (Emery and Devane, 2007a), think aloud designing (Eaglestone et al., 2007), designer diaries (Naur, 1983) , design thinking (Lugmayr et al., 2014), and search conferences (Emery and Devane, 2007b), etc.

Design ethnography toolkit (DE). In design ethnography additional tools need to be used along with intervention. Aside from co-planning and co-designing, Kilbourn (2013) suggests perceptual synthesis (forms of conceptual association and synthesis through visual means), experience juxtaposing (comparing experiences through games or other means), and potential relationing (forms of performance as ways to explore the social embeddedness of possible future practices).

While the notion of choosing the right toolkit for the right way of doing ethnography has a certain pragmatic appeal, it is an over simplification. The complete ethnographic toolkit is, of course, available to the design ethnographer, but which ones are useful will depend upon the context. Further, the generative nature of this engagement means that it might be appropriate to create or improvise original tools that fit the unique situation that every design setting implies.

A diagrammatic representation of the general framing and process for design ethnography is depicted in Figure 1 . The concepts underlying this representation are largely adapted for use in information systems from Gunn, Otto and Smith (Gunn et al., 2013) and Wasson (2002). This figure situates the three forms of design ethnography in relation to design. The basic symbols in Figure 1 are:

- Boxes: Design processes

- Boxes with folded edge: Ethnographies

- Boxes with rounded edges: Grouped design processes

- Quadrangle box: Designed Artifacts

- Arrows: Staging (arrow flows from an element that stages-or provides a stage for-the following element.

- Arrows flowing from a dot: Producing (arrow flows from an element that produces the following element).

- Circled cross: Optional flows

In DE the concept of ethnography is considered as a descriptive element and the concept of design is considered as an intervention. Ethnographies are activities that are largely oriented toward capturing knowledge about the design activities. The design activities are largely organized as change-oriented and future-oriented interventions that trigger deep knowledge and understanding about the social and cultural aspects of the setting. In Figure 1 the design activities that provide the venues to produce the ethnographies are shown separately from the ethnographies that are produced from the design activities. 


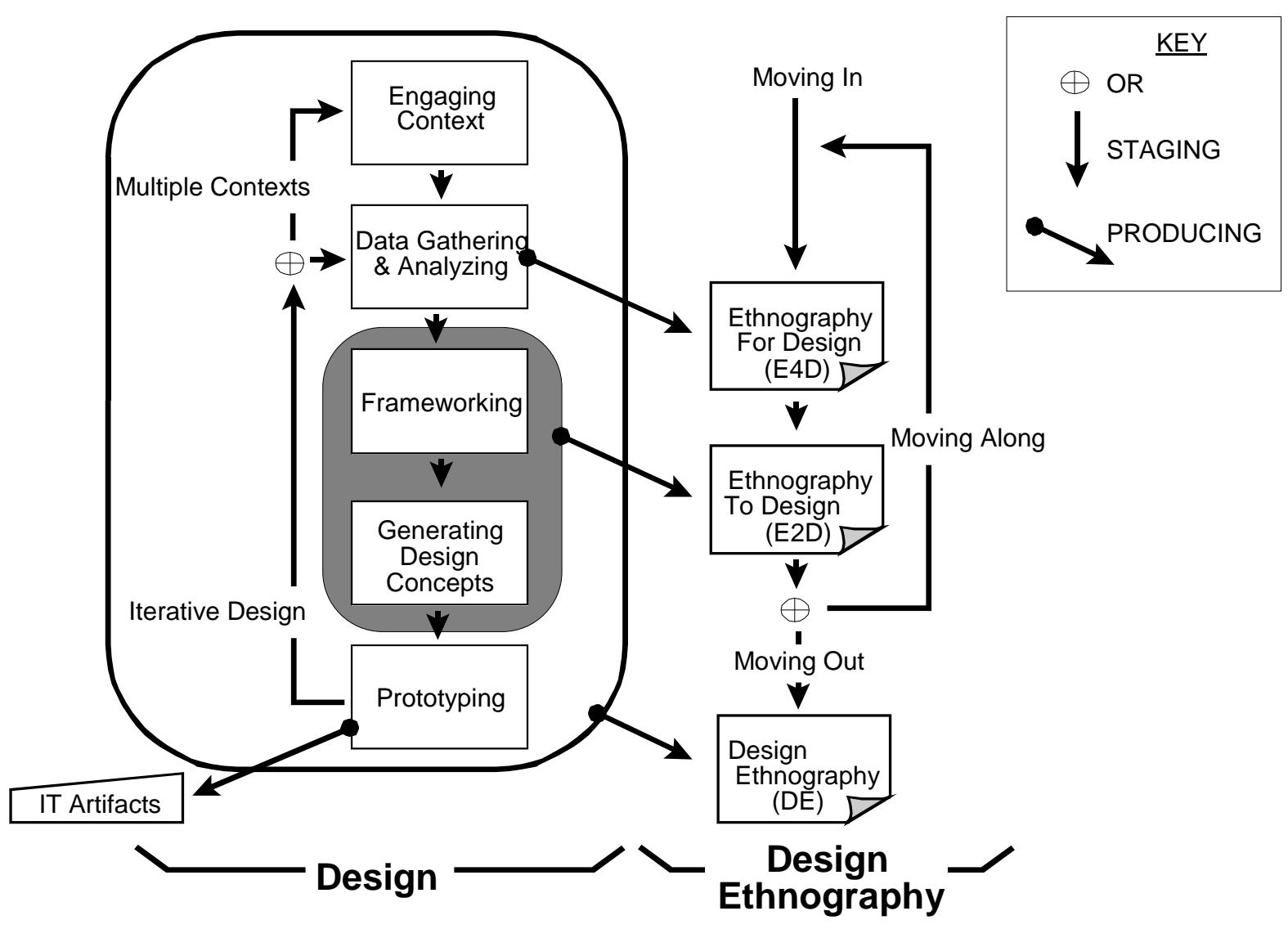

Figure 1. A Framework for Design Ethnography in IS

Engaging Context. The first process encountered in the design aspect involves establishing the context for the forthcoming design activities. The process of engagement-setting may have formal (e.g., contracts, non-disclosure agreements, human subject approvals, etc.) and/or informal arrangements. This process may involve the researcher joining with other designers in a new design project for a new context or it might instead involve the researcher joining designers in their ongoing design activities for an ongoing design project. The process may include setting ground rules for any dilemmas that might arise from engaging a researcher in practical action. Such dilemmas might include the conflicts in the researchers' goals as a researcher and their goals as a designer, or conflicts between the ethics of research and the ethics of practice (Rapoport, 1970). Engaging the context sets the stage for data gathering and analysis.

Moving In. While the research context is being settled, the trajectory of the researcher is toward joining the design activities of the research setting. It is at this moment that the researcher becomes part of the research context: an active participant in the practice of designing. Moving in connotes both a changeof-life for the researcher and others in the context. There is an orientation of doing research through practice rather than doing research on practice (Kilbourn, 2013). Moving in sets the stage for making a descriptive E4D. 
Action research has activities that are similar to some activities found in 'Engaging context' and 'Moving in'. Engaging the context might involve formal aspects similar to the researcher-client agreement of canonical action research (Davison et al., 2004). Moving in may involve the more informal merger of the practices of the research subjects into the practices of the researchers in a way similar to participatory action research (Whyte et al., 1991). Like Action Design Research (Sein et al., 2011), DE builds on the similarities in design science and action research (Järvinen, 2007). But rather than beginning with a problem (problem formulation or problem awareness, Argyris and Schön, 1991), DE begins with the immersion of the researcher into the design practices of the subjects (which may be in progress or ongoing). In this way, DE remixes the opening stages of design science, action research and ethnography, and then separates them differently: into moving in from engaging the context. While engaging the context has something of a design functional role or client infrastructure aspect in the research process, moving in is closer to the participative action research notions of joining in a social situation. Moving in extends to the physical, social and cultural immersion that typically situates ethnographers for their studies. Together, context engagement and moving in may also entail an unwritten social contract that complements any more formal agreements arising from engaging the context.

Data Gathering and Analyzing. While this process is common to all forms of ethnography, in DE it may include data gathering and analysis that is anchored more to practical action (such as questionnaires, objective observations, instrumented measurements of material performance, etc.) for use in designing the intended artifacts. One further goal of the analysis is to detect patterns among the instances of behavior in the design setting. By participating in the collection and analysis of information needed for the design, the researcher not only brings ethnographic skills into the data collection process, but also gains insight into the cultural and societal aspects that determine what information designers determine is important for the design. This information sets the stage for frameworking.

Ethnography for Design (E4D). As described earlier in this paper, E4D is the first way of joining ethnography and design. The ethnography is applied as practical action in discovering information and data to enable design (Salvador et al., 1999; Squires and Byrne, 2002; Wasson, 2000). Having ethnographic data about and an ethnographic analysis of the setting for the designed artifact sets the stage for E2D.

Frameworking. This process involves further interpretation of the resulting data and information gathered, both practical and ethnographic, in the context of the design task at hand. Frameworking involves organizing these results by attaching the designers' cultural or social attributes that bring meaning to the collective whole. These cultural frames provide the designers' shared understanding of the technical, cultural and social context of the design actions they are about to undertake in designing artifacts (Agar, 1986). Such frames are a complex form of sensitizing concepts that provide indicators for design directions, a starting point from which to make design concepts (Bowen, 2006).

Frameworking marks the transition point at which the designers transform the foregoing research in the design context into concepts that will drive their design decisions. By being one of the frameworkers, the researcher is forced by their role to register their own cultural framework against those of the others in the setting. The process offers particular insight into how the designers accommodate differing cultural and societal values present in the setting.

Generating Design Concepts. The generative aspect of design ethnography is centered in this process. The engagement of the ethnographic researcher as a participant observer in practical acts of creation, innovation, and improvisation of designs is one hallmark of DE. Like other designers in the setting, this aspect may mean working in private to understand the sensitizing concepts. Like other designers, the researcher may participate in brainstorming sessions. In information systems, the researcher often will 
have recognizable expertise in the design setting (e.g., technologies involved) and may be asked to critique tentative design concepts under consideration. By being one of the designers and participating constructively in generating the design concepts, the researcher gains insight into the designerly aspects of cultural and societal values present in the setting. Generating Design Concepts sets the stage for prototyping. Together with Frameworking, Generating Design Concepts provides the venue for producing ethnographies about design (E2D).

Ethnography to Design (E2D). As mentioned earlier, E2D provides the second way to integrate ethnography and design. In this way the researcher uses an ethnographic frame to study the cultural and societal aspects of the designers. However, within a design ethnography framework, this is a participative study. The researcher is not only studying the designers, but participating by doing a share of the designing. E2D sets the stage for either moving on to study the designers in a different context, or alternatively moving out to conclude the research with DE.

Moving Along. When the context of the design engagement concludes, or otherwise becomes suitable for the researcher to depart (e.g., the researcher is able to hand-off design activities to someone else), two different trajectories are available to the researcher. One is moving along, in which the researcher moves along to a different design setting for the research. Moving along to other settings can broaden the knowledge scope of the ethnography and develop knowledge that spans multiple contexts. It not only provides an understanding beyond a particular place or configuration, but also how actions in different contexts mediate the relationship between materials and knowledge (Kilbourn, 2013). Since the design ethnography is a continuation of the design project in differing contexts it may not require moving in again.

Prototyping. Once the design concepts have been shaped by the designers, design ethnography in IS assumes that a prototyping activity will follow. There are two reasons for this assumption. One reason regards the high frequency with which prototyping is used in IS settings. Such settings add a contingency character to designs that indicate the design concepts are conditioned on success in a complex context. Approaching such contexts synthetically, that is, by introducing an artifact and studying the interactions of the artifact with its environment, begs for a prototyping style of design approach (Simon, 1996). A second reason follows from the open-ended assumptions of design ethnography. Such assumptions imply that all design activities are continuous, ongoing, or emergent. For design ethnographer, designing is not a human action that ever completes. Hence, just like a prototype, any artifact staged by design concepts is unfinished, contingent on future design concepts that are yet unknown (Drazin, 2013). By helping to construct the artifacts implied by the design, the researcher learns about the impacts of the prototype on its setting and vice versa. It reveals in a concrete way the relationship between design and use: "first designers design, then users use" (Redström, 2013, p. 83). These phenomena interact in ways that are wholly reciprocal. Design defines use and use defines design. Prototyping makes the relation more apparent to the researcher. Because of the openness of design, prototyping sets the stage for iterative design, a return to earlier processes to restart the data gathering, or alternatively to shift to a new context to provide experience with the design processes in multiple contexts. Prototyping also produces a specimen(s) of the rich range of IT artifacts. Together with the other design processes, the entire design process provides the venue for producing design ethnographies.

IT Artifacts. There are various descriptions and definitions of IT artifacts. An appropriate definition for our purposes is "that bundle of material and cultural properties packaged in some socially recognizable form such as hardware and/or software" (Orlikowski and lacono, 2001, p. 121). In keeping with this definition, artifacts can be seen to embody social and cultural values as a physical or symbolic representation (Ehn, 1988). As such the IT artifacts themselves have value for ethnographers. Once 
produced, the artifacts become part of the context. It is for this reason that we show the IT artifacts in Figure 1 outside of the design process. However, IT artifacts matter to the design ethnographer in two ways. First, their production is part of the design process. Second, they become part of the context of future designing activity, and as such become one of the future sources for data gathering and analysis.

Moving Out. The researcher's exit from the design setting(s) does not conclude the design ethnography. Rather, the researcher now needs to write up the findings and produce a design ethnography. Similar to canonical action research, theory needs to play a prominent role in the write up (Davison et al., 2012). This suggests that the DE that is produced should be one that is more focused on the wider boundaries of knowledge proceeding from the research (Kilbourn, 2013). However, these boundaries should also extend to the generation of conceptual alternatives to current theory and proposed explanations for future possibilities.

Similar to the situation with engaging the context and moving in, DE distinguishes between completing the ethnographer's more functional role in the design process from concluding their physical, social and cultural immersion in the design setting. The former involves wrapping up the design aspect, delivering artifacts and closing any informal or formal canonical-action-research-style researcher-client agreements. The latter (moving out) wraps up the physical social and cultural aspect similar to disengaging in ethnography or participative action research. But together these both contribute to wrapping up the design ethnographic aspect.

Figure 2 (adapted from Wasson's "bow tie" model) illustrates the organization of processes that ensues from the integration of ethnography and design (Wasson, 2002, p. 84). As the processes progress (left-to-right), the activities of ethnographic research at the left wing are tied to the activities of design at the right wing by means of the sensitizing concepts arising from frameworking.

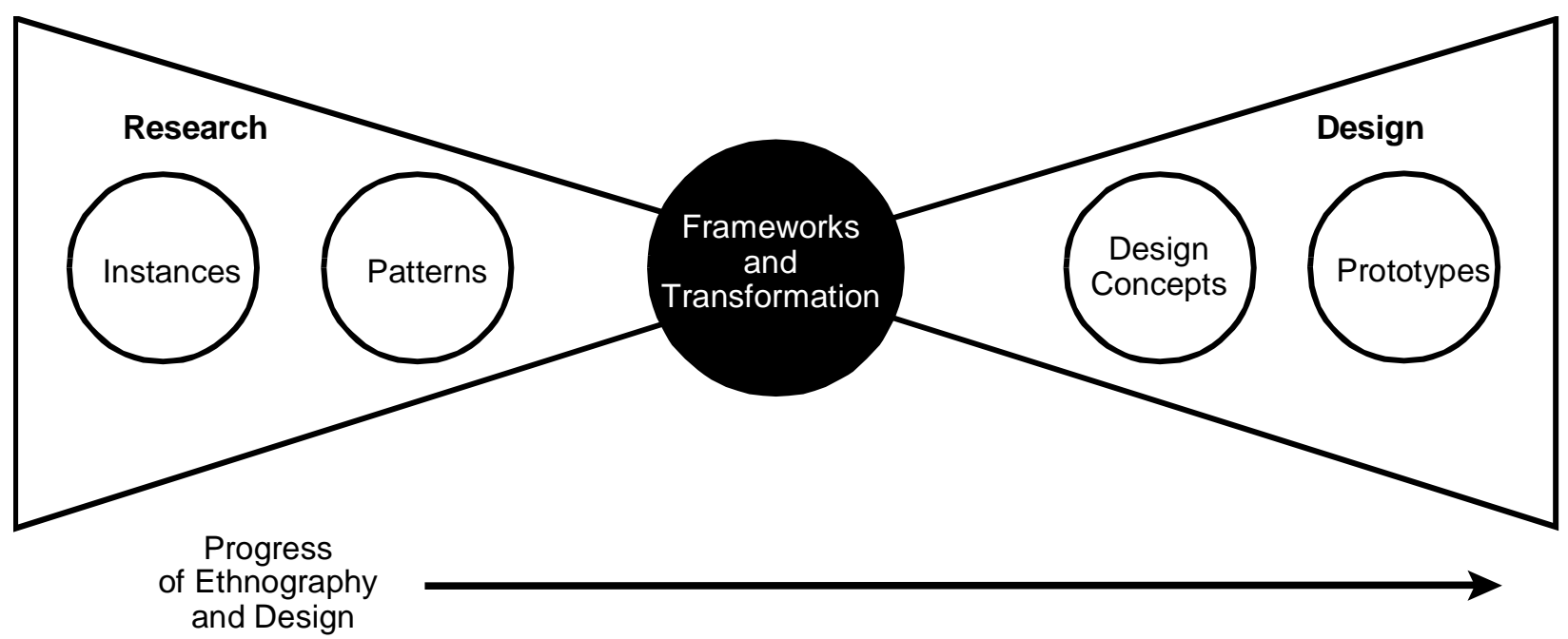

Figure 2. The Bow Tie Model of Ethnography and Design (adapted from Wasson, 2002).

\section{Criteria for Evaluating Design Ethnography}

Having discussed design ethnography and how it can be conducted, we now suggest criteria by which a design ethnography can be judged. These criteria are offered in the spirit of helping design ethnographers to produce a research contribution that is seen as being of high quality by editors and reviewers. These criteria should also be helpful to those who, while not doing design ethnography themselves, want to better understand how design ethnography can be evaluated. 
Various criteria have been suggested for evaluating traditional ethnographies. Golden-Biddle and Locke (1993) suggest three criteria. These three criteria are as follows:

1. Authenticity

2. Plausibility

3. Criticality

Authenticity means that the ethnographer needs to convince the reader that they were immersed in the field. This can be achieved by providing information about the research method and the findings. This criterion is similar to that suggested by Myers, who says that the researcher needs to provide evidence that they have indeed been there and lived in the situation for some time (Myers, 1999). This evidence can be provided by including thick descriptions of social and cultural activities, direct quotations from interviews, and so forth. Plausibility relates to the story that the ethnography tells: is the account believable and does it contribute to new knowledge? A contribution to knowledge in a particular discipline is usually assessed by the extent to which the research project addresses a gap or problem in the research literature. Criticality is a form of cultural critique in which the researcher is required to critically reflect and challenge the existing cultural norms and values. As well as examining their own taken-for-granted assumptions, ethnographers are encouraged to imagine new ways of thinking and acting (Schultze, 2000).

For design science research, Hevner at al. (2004) suggest seven guidelines. These seven guidelines are as follows:

1. Design as an Artifact

2. Problem Relevance

3. Design Evaluation

4. Research Contributions

5. Research Rigor

6. Design as a Search Process

7. Communication of Research

The first guideline suggests that design science research (DSR) must produce a viable artifact in the form of a construct, a model, a method, or an instantiation. The second suggests that the objective of DSR is to develop technology-based solutions to important and relevant business problems. The third guideline says that the utility, quality, and efficacy of a design artifact must be rigorously evaluated. The fourth suggests that the DSR project must make a new contribution to knowledge. The fifth says that there should be research rigor in the design and evaluation of the artifact. The sixth guideline says that design is a search process for the best design in a given context. The seventh guideline suggests that the results of the DSR project must be effectively communicated (Hevner et al., 2004).

Table 1 provides a suggested set of criteria for the conduct and evaluation of a high quality design ethnography. It combines the relevant guidelines for design science research with the three criteria for ethnographic research. 


\begin{tabular}{|c|l|}
\hline Criterion & \multicolumn{2}{l|}{ Requirement } \\
\hline 2. Shared experience in design & $\begin{array}{l}\text { The design ethnographer should demonstrate their } \\
\text { experience in design and their understanding of social } \\
\text { and cultural practices and values. }\end{array}$ \\
\hline 3. Insight into design culture & $\begin{array}{l}\text { The design ethnographer should describe a theory that } \\
\text { explains how and why people create artifacts and adapt } \\
\text { them to their environment. }\end{array}$ \\
\hline 4. Plausibility & $\begin{array}{l}\text { The design ethnographer should explain why the artifact } \\
\text { and design experience is important to the subjects in the } \\
\text { field, providing rich insight into their culture }\end{array}$ \\
\hline 5. Criticality & $\begin{array}{l}\text { The design ethnography should be plausible and a } \\
\text { contribution to new knowledge in IS; it should } \\
\text { demonstrate insight into the meaning and relevance of } \\
\text { the design practices in the particular context to designers } \\
\text { in other contexts. }\end{array}$ \\
\hline 6. Research rigor & $\begin{array}{l}\text { The design ethnographer should critically reflect upon } \\
\text { and challenge taken-for-granted assumptions and be } \\
\text { encouraged to imagine new ways of designing artifacts. }\end{array}$ \\
\hline & $\begin{array}{l}\text { The design ethnographer should explain their active } \\
\text { engagement throughout the design process. The design } \\
\text { ethnographer should demonstrate authenticity. }\end{array}$ \\
\hline
\end{tabular}

Table 1. Requirements for design ethnography

The first criterion draws attention to the fact that design ethnography is not design science research. In DSR the contribution usually revolves around artifacts produced by the study (Gregor and Hevner, 2013), but in DE the artifact is a byproduct of the study. In design ethnography it is the shared design experience that is key because it is a venue for learning about social and cultural practices and values.

The second criterion justifies the study's theoretical research contribution. Action research can involve both focal and instrumental theories that prescribe specific action and are thereby validated empirically (Davison et al., 2012). Design theories tend to provide teleological explanations of artifact attributes (Baskerville and Pries-Heje, 2010). Design ethnographic theory is more often reflective, an idiographically-based explanation for how and why people create artifacts and adapt them within a particular cultural context (Ingold, 2008).

The third criterion suggests that the design ethnographer needs to provide rich insights into the culture of the subjects in the field (Myers, 1999). An explanation of the design experience and the creation of the artifact is more important in DE than an evaluation of the artifact itself. This again distinguishes DE from DSR.

The fourth criterion says that the design ethnography should be plausible (Golden-Biddle and Locke, 1993) and a contribution to new knowledge in information systems. The ethnography should be relevant to current concerns in IS and demonstrate how the findings in the particular context are relevant to designers in other contexts (Schultze, 2000). 
The fifth criterion suggests that the design ethnographer should critically reflect upon and challenge taken-for-granted assumptions (Myers, 1999). They should also be encouraged to imagine new ways of designing artifacts. This element of criticality is potentially one of the benefits for organizations sponsoring the research.

The sixth criterion suggests that the design ethnographer must demonstrate authenticity (Golden-Biddle and Locke, 1993). The design ethnographer needs to explain their active engagement throughout the design process. This can be done, for example, by providing thick descriptions of the field, using direct quotations from interviews, and including sufficient information about the research method.

\section{Discussion and Conclusions}

Design ethnography is a new form of ethnography that involves the active engagement of the researcher. DE is "highly generative" in nature and is future-oriented, reflective, critical, intuitive, interpretive, creative, and improvisational (Kilbourn, 2013, p. 77). Otto and Smith (2013, p. 1) refer to this as a "distinct style of knowledge". It can entail theorizing beyond the normal boundaries of science. For example, these boundaries extend to the generation of conceptual alternatives to current theory and deliver explanations for future possibilities. Within these extended boundaries we include the ways in which design might change human behavior. This extension implies that, by designing the artifacts in human settings, we are necessarily entangled in designing expected human behavior (Tromp and Hekkert, 2013). Hence, rather than being a passive observer of changes in human behavior or organizations and human society more generally, the design ethnographer becomes an active participant in shaping these changes.

We have preferred the term design ethnography to describe this new approach to information systems research. The term design anthropology has been used by some scholars in the anthropology literature as an umbrella term to encompass the use of the three different relationships between ethnography and design described earlier (Gunn et al., 2013). In anthropology, the term design ethnography sometimes implies only ethnography for design, which is just one form of design ethnography (Wasson, 2002). However, because this confusion has not developed in the information systems field, we believe that design ethnography is a more suitable all-encompassing term. We are information systems scholars, not anthropologists, and hence for us design ethnography is a better term as it clearly indicates that $D E$ is a research method.

$D E$ is an ethnographic method that intervenes in the research setting. As mentioned above, existing forms of advocacy ethnography have been equated to participatory action research (Sanjek, 2004). But much of this work sees such advocacy as a later stage product of the ethnography, unlike DE where the intervention is a formative part of the research practice. Still, any degree of intervention skirts the boundaries of action research methods and any degree of design skirts the boundaries of design science research. As advocates of design science research have discovered, it becomes problematic to distinguish action research from design science research. Like DE, both of these methods aim to intervene, solve a problem, contribute new scientific knowledge, and improve a social-technical situation (Järvinen, 2007). Action research and design science merge easily, and studies using action research may satisfy design science criteria and vice-versa (Cole et al., 2005; Loebbecke and Powell, 2009; Sein et al., 2011). Despite such overlapping boundaries, each of these research approaches differs at its center. Action Research centers the change in a difficult social setting; design science research centers the generation of a novel artifact in a problem context; design ethnography centers the revelations of social and cultural values present in design practice. 
Table 2 provides a brief summary of the differences between action research, design science research, traditional ethnography and design ethnography. It can be seen that there are important differences including their conceptual origin (where the methodology came from) and the research aim.

Unlike other forms of ethnography, design ethnography has a future-orientation involving prescriptive theory and intervention. Unlike action research and design science, design ethnography seeks its validity in richly detailed, "thick" descriptions, and aims mainly at delivering knowledge about social and cultural practices and values. Like ethnography and action research, design ethnography usually takes a scope of research that contributes cultural knowledge based on a singular setting (idiographic), while design science usually applies or develops theories that apply to a class of problems and the artifact (nomothetic) (Ingold, 2008; Walls et al., 1992). Like design science, the research activities in DE center around the design of IT artifacts, a characteristic not shared with the others.

All of these research methodologies leave residual benefits behind in the empirical setting that has provided a research context. These benefits are research offshoots that sometimes motivate the participation by the people in the context. Unlike any of the other approaches, the main residual benefit left behind in the research setting or context by design ethnography is the shared design knowledge that has benefited from social and cultural translation into the context. Each of the others typically leave a different central residual benefit. 


\begin{tabular}{|l|l|l|l|l|}
\hline Characteristic & Action Research & \multicolumn{1}{l|}{$\begin{array}{l}\text { Design Science } \\
\text { Research }\end{array}$} & Ethnography & \multicolumn{2}{l|}{$\begin{array}{l}\text { Design } \\
\text { Ethnography }\end{array}$} \\
\hline Conceptual origin & $\begin{array}{l}\text { Organizational } \\
\text { Psychology }\end{array}$ & $\begin{array}{l}\text { Engineering and } \\
\text { Computer Science }\end{array}$ & Anthropology & $\begin{array}{l}\text { Anthropology and } \\
\text { Design Practice }\end{array}$ \\
\hline $\begin{array}{l}\text { Temporal } \\
\text { orientation }\end{array}$ & Future & Future & Past & Future \\
\hline $\begin{array}{l}\text { Temporal mode } \\
\text { of theorizing }\end{array}$ & Prescriptive & Prescriptive & Descriptive & $\begin{array}{l}\text { Descriptive and } \\
\text { Prescriptive }\end{array}$ \\
\hline Research scope & Idiographic & Nomothetic & Idiographic & Idiographic \\
\hline $\begin{array}{l}\text { Empirical mode } \\
\text { Research activity }\end{array}$ & $\begin{array}{l}\text { Intervention } \\
\text { experiments }\end{array}$ & Invention & $\begin{array}{l}\text { Immersed } \\
\text { observer }\end{array}$ & $\begin{array}{l}\text { Immersed in } \\
\text { Intervention }\end{array}$ \\
\hline Validation & Practical outcome & Evaluation & Fieldwork & $\begin{array}{l}\text { Design IT artifacts } \\
\text { during fieldwork }\end{array}$ \\
\hline $\begin{array}{l}\text { Main context } \\
\text { residual }\end{array}$ & Social change & IT artifacts & $\begin{array}{l}\text { Shared cultural } \\
\text { knowledge }\end{array}$ & $\begin{array}{l}\text { Shared design } \\
\text { knowledge }\end{array}$ \\
\hline Research aim & $\begin{array}{l}\text { Practical and } \\
\text { theoretical } \\
\text { knowledge about } \\
\text { society and } \\
\text { psychology }\end{array}$ & $\begin{array}{l}\text { Technological } \\
\text { knowledge about } \\
\text { artifacts }\end{array}$ & $\begin{array}{l}\text { Knowledge about } \\
\text { social and cultural } \\
\text { practices and } \\
\text { values }\end{array}$ & $\begin{array}{l}\text { Knowledge about } \\
\text { social and cultural } \\
\text { practices and } \\
\text { values }\end{array}$ \\
\hline
\end{tabular}

Table 2. Comparative characteristics of action research, and design science research, ethnography and design ethnography.

The implications of design ethnography for IS research and practice are as follows. First, since ethnography is one of the most in-depth research methods possible, DE might be able to provide deep insights into design practices and processes. It could inform future action research and design science research projects. Second, DE allows ethnographers in IS a more active role in the field. Rather than being passive observers, ethnographers can now share their expertise without feeling they have made a wreck of their research design. Design ethnography is simply another kind of ethnography in which the researcher is actively engaged with others in a future-oriented way: designing, creating, innovating, and improvising artifacts within a social and cultural setting. Third, DE, like action research and design science research, is another way of bridging the gap between research and practice. Many of the tools in the design ethnographer's toolkit require and enable the active engagement of the design ethnographer with users and IS practitioners.

There are some limitations of DE. First, how well can an ethnographer do ethnographic fieldwork as well as design? It is clear that there will be considerable variation in the extent to which an ethnographer does one or the other, and the balance will depend on the situation. However, a design ethnographer must meet the criteria for DE discussed earlier. Of course, since there are different kinds 
of ethnography, we are not suggesting that all ethnographers in IS need to do DE. Second, if a researcher announces to people in the field that they are doing $D E$, to what extent might this raise expectations? The people in the field might become impatient with the design ethnographer if the fieldwork takes too long. Also, if the researcher focuses more on the descriptive than the prescriptive aspect, the people in the field might feel that that designs produced by the researcher are too tentative. A third limitation of DE is that we do not have as yet any clear ethical guidelines for this kind of research. Like action research and DSR, the active intervention of the researcher in human affairs raises many ethical issues. Space limitations prevent a detailed examination of this issue, but we note that Myers and Venable (2014) have recently suggested a set of ethical principles for design science research in information systems. A future research project might consider whether these principles apply equally well to design ethnography.

\section{Acknowledgements}

The authors gratefully acknowledge their inspiration by Thomas Binder's comments at the Roskilde University 2014 Doctoral Seminar in Designing Human Technologies.

\section{References}

Agar, M. (1986) Speaking of Ethnography, Newbury Park, Calf: Sage.

Argyris, C. and Schön, D. (1991) Participatory Action Research and Action Science Compared, in: Whyte, W.F. (Ed.), Participatory Action Research, Newbury Park, N.J.: Sage, pp. 85-96.

Avison, D.E. and Myers, M.D. (1997) Information Systems and Anthropology: An Anthropological Perspective on IT and Organizational Culture, Information Technology \& People 10(3): 43-56.

Ball, L.J. and Ormerod, T.C. (2000) Putting ethnography to work: the case for a cognitive ethnography of design, International Journal of Human-Computer Studies 53(1): 147-168.

Barab, S.A., Thomas, M.K., Dodge, T., Squire, K. and Newell, M. (2004) Critical Design Ethnography:

Designing for Change, Anthropology \& Education Quarterly 35(2): 254-268.

Baskerville, R. and Myers, M. (2004) Special issue on action research in information systems: Making IS research relevant to practice--foreword, MIS Quarterly 28(3): 329-335.

Baskerville, R. and Pries-Heje, J. (2010) Explanatory Design Theory, Business \& Information Systems Engineering 2(5): 271-282.

Berglund, E. (2014) Book review of 'Design anthropology: theory and practice', Journal of the Royal Anthropological Institute 20(2): 378-379.

Bjerknes, G., Ehn, P. and Kyng, M. (1987) Computers and democracy-a Scandinavian challenge, Brookfield, VT: Gower Publishing Ltd.

Bowen, G. (2006) Grounded theory and sensitizing concepts, International journal of qualitative methods 5(3): 12-23.

Campbell, J., Fletcher, G. and Greenhill, A. (2009) Conflict and identity shape shifting in an online financial community, Information Systems Journal 19(461-478.

Cole, R., Purao, S., Rossi, M. and Sein, M.K. (2005) Being Proactive: Where Action Research Meets Design

Research, in: Avison, D., Galletta, D., DeGross, J.I. (Eds.), Proceedings of the Twenty-Sixth International Conference on Information Systems, Las Vegas, Nevada, USA: Association for Information Systems, pp. 325-336. 
Davies, L.J. (1991) Researching the Organisational Culture Contexts of Information Systems Strategy: A Case Study of the British Army, in: Nissen, H.-E., Klein, H.K., Hirschheim, R.A. (Eds.), Information Systems Research: Contemporary Approaches and Emergent Traditions, Amsterdam: North-Holland, pp. 145-167. Davies, L.J. and Nielsen, S. (1992) An ethnographic study of configuration management and documentation practices in an Information Technology centre, in: Kendall, K.E., Lyytinen, K., De Gross, J.I. (Eds.), The Impact of Computer Supported Technology on Information Systems Development, Amsterdam: North Holland, pp. 179-192.

Davison, R., Martinsons, M.G. and Kock, N. (2004) Principles of canonical action research, Information Systems Journal 14(1): 65-86.

Davison, R.M., Martinsons, M.G. and Ou, C.X.J. (2012) The Roles of Theory in Canonical Action Research, MIS Quarterly 36(763-786.

Denny, R. (2002) Communicating with Clients, in: Squires, S., Byrne, B. (Eds.), Creating Breakthrough ideas: the collaboration of anthropologists and designers in the product development industry, Westport Conn: Bergin \& Garvey, pp. 147-159.

Drazin, A. (2013) The social life of concepts in design anthropology, in: Gunn, W., Otto, T., Smith, R.C. (Eds.), Design anthropology: theory and practice, London: Bloomsbury Academic, pp. 33-50.

Eaglestone, B., Ford, N., Brown, G.J. and Moore, A. (2007) Information systems and creativity: an empirical study, Journal of Documentation 63(4): 443.

Ehn, P. (1988) Work-Oriented Design of Computer Artifacts, 2 ed, Stockholm: Arbetslivscentrum. Emery, M. and Devane, T. (2007a) Participative Design workshop, in: Holman, P., Devane, T., Cady, S. (Eds.), The Change Handbook: The Definitive Resource on Today's Best Methods for Engaging Whole Systems... San Francisco: Berrett-Koehler, pp. 419-435.

Emery, M. and Devane, T. (2007b) Search Conference, in: Holman, P., Devane, T., Cady, S. (Eds.), The Change Handbook: The Definitive Resource on Today's Best Methods for Engaging Whole Systems... San Francisco: Berrett-Koehler, pp. 347-364.

Ewart, I.J. (2013) Designing by Doing, Building Bridges in the Highlands of Borneo, in: Gunn, W., Otto, T., Smith, R.C. (Eds.), Design anthropology: theory and practice, London: Bloomsbury Academic, pp. 85-99. Gatt, C. and Ingold, T. (2013) From Description to Correspondence: Anthropology in Real Time, in: Gunn, W., Otto, T., Smith, R.C. (Eds.), Design anthropology: theory and practice, London: Bloomsbury Academic, pp. 139-158.

Germonprez, M. and Hovorka, D.S. (2013) Member engagement within digitally enabled social network communities: new methodological considerations, Information Systems Journal 23(525-549.

Golden-Biddle, K. and Locke, K. (1993) Appealing Work: An Investigation of How Ethnographic Texts Convince, Organization Science 4(4): 595-616.

Goldkuhl, G. (2012) Pragmatism vs interpretivism in qualitative information systems research, European Journal of Information Systems 21(2): 135-146.

Gregor, S. and Hevner, A.R. (2013) Positioning and Presenting Design Science Research for Maximum Impact, MIS Quarterly 37(2): 337-361.

Gregor, S. and Jones, D. (2007) The Anatomy of a Design Theory, Journal of the Association for Information Systems 8(5): 312-335.

Gunn, W. and Donovan, J. (2013) Design and Anthropology, Burlington, Vt.: Ashgate.

Gunn, W., Otto, T. and Smith, R.C. (2013) Design anthropology: theory and practice, London: Bloomsbury Academic.

Harvey, L. (1997) A genealogical exploration of gendered genres in IT cultures, Information Systems Journal 7(153-172.

Harvey, L. and Myers, M.D. (1995) Scholarship and practice: the contribution of ethnographic research methods to bridging the gap, Information Technology \& People 8(3): 13-27. 
Hatala, M. and Wakkary, R. (2005) Ontology-Based User Modeling in an Augmented Audio Reality System for Museums, User Modeling and User - Adapted Interaction 15(3-4): 339-380.

Hevner, A.R. (2007) A Three Cycle View of Design Science Research, Scandinavian Journal of Information Systems 19(2): 87-92.

Hevner, A.R., March, S.T., Park, J. and Ram, S. (2004) Design Science In Information Systems Research, MIS Quarterly 28(1): 75-105.

Holzblatt, K. and Beyer, H. (1993) Making customer-centered design work for teams, Communications of the ACM 36(10): 93-103.

Hughes, J.A., Randall, D. and Shapiro, D. (1992) Faltering from ethnography to design, ACM 1992

Conference on Computer-Supported Cooperative Work: Sharing Perspectives, New York: ACM Press, pp.

115-123.

Ingold, T. (2008) Anthropology is not ethnography, Proceedings of the British Academy, The British

Academy, Oxford University Press, pp. 69-92.

Järvinen, P. (2007) Action Research is Similar to Design Science Quality and Quantity 41(1): 37-54.

Kilbourn, K. (2013) Tools of Movement and Engagement: Design Anthropology's Style of Knowing, in:

Gunn, W., Otto, T., Smith, R.C. (Eds.), Design anthropology: theory and practice, London: Bloomsbury Academic, pp. 68-82.

Kvasny, L., Trauth, E.M. and Morgan, A.J. (2009) Power relations in IT education and work: the intersectionality of gender, race, and class, Journal of Information, Communication and Ethics in Society 7(96-118.

Lee, J.C. and Myers, M.D. (2004) Dominant actors, political agendas, and strategic shifts over time: A critical ethnography of an enterprise systems implementation, Journal of Strategic Information Systems 13(4): 355-374.

Leonardi, P.M. (2011) When Flexible Routines Meet Flexible Technologies: Affordance, Constraint, and the Imbrication of Human and Material Agencies, MIS Quarterly 35(147-167.

Leonardi, P.M. (2013) When Does Technology Use Enable Network Change in Organizations? A Comparative Study of Feature Use and Shared Affordances, MIS Quarterly 37(749-775.

Loebbecke, C. and Powell, P. (2009) Furthering distributed participative design, Scandinavian Journal of Information Systems 21(1): 77-106.

Lugmayr, A., Stockleben, B., Zou, Y., Anzenhofer, S. and Jalonen, M. (2014) Applying "Design Thinking" in the context of media management education, Multimedia Tools and Applications 71(1): 119-157.

Macaulay, C., Sloan, D., Jiang, X., Forbes, P., Loynton, S., Swedlow, J.R. and Gregor, P. (2009) Usability and User-Centered Design in Scientific Software Development, IEEE Software 26(1): 96-102.

March, S.T. and Smith, G.F. (1995) Design and natural science research on information technology, Decision Support Systems 15(4): 251-266.

McKay, J., Marshall, P. and Hirschheim, R. (2012) The design construct in information systems design science, Journal of Information Technology 27(2): 125-139.

Myers, M.D. (1997) Critical Ethnography in Information Systems, in: Lee, A.S., Liebenau, J., DeGross, J.I. (Eds.), Information Systems and Qualitative Research, London: Chapman and Hall, pp. 276-300.

Myers, M.D. (1999) Investigating Information Systems with Ethnographic Research, Communications of the AIS 2(23): 1-20.

Myers, M.D. (2013) Qualitative Research in Business \& Management, 2nd ed, London: Sage Publications. Myers, M.D. and Newman, M. (2007) The qualitative interview in IS research: Examining the craft, Information and Organization 17(1): 2-26.

Myers, M.D. and Venable, J. (2014) A Set of ethical principles for design science research in information systems, Information \& Management: 1-9. 
Myers, M.D. and Young, L.W. (1997) Hidden Agendas, Power, and Managerial Assumptions in Information Systems Development: An Ethnographic Study, Information Technology \& People 10(3): 224-240.

Naur, P. (1983) Program development studies based on diaries, in: Green, T., Payne, S., van der Veer, G. (Eds.), Psychology of Computer Use, London: Academic Press, pp. 159-170.

Orlikowski, W.J. (1991) Integrated Information Environment or Matrix of Control? The Contradictory Implications of Information Technology, Accounting, Management and Information Technologies 1(1): 942.

Orlikowski, W.J. and lacono, C.S. (2001) Research commentary: Desperately seeking "IT" in IT research A call to theorizing the IT artifact, Information Systems Research 12(2): 121-134.

Orlikowski, W.J. and Robey, D. (1991) Information Technology and the Structuring of Organizations, Information Systems Research 2(2): 143-169.

Otto, T. and Smith, R.C. (2013) Design Anthropology: A Distinct Style of Knowing, in: Gunn, W., Otto, T., Smith, R.C. (Eds.), Design anthropology: theory and practice, London: Bloomsbury Academic, pp. 1-29. Peffers, K., Tuunanen, T., Rothenberger, M.A. and Chatterjee, S. (2008) A Design Science Research Methodology for Information Systems Research, Journal of Management Information Systems 24(3): 4577.

Rapoport, R. (1970) Three Dilemmas of Action Research, Human Relations 23(6): 499-513.

Ravishankar, M.N., Pan, S.L. and Myers, M.D. (2013) Information technology offshoring in India: a postcolonial perspective, European Journal of Information Systems 22(4): 387-402.

Redström, J. (2013) Introduction: Defining Moments, in: Gunn, W., Donovan, J. (Eds.), Design and Anthropology, Burlington, Vt.: Ashgate, pp. 83-99.

Ribes, D. and Finholt, T. (2009) The long now of technology infrastructure: articulating tensions in development, Journal of the Association for Information ... 10(375-398.

Salvador, T., Bell, G. and Anderson, K. (1999) Design Ethnography, Design Management Journal (Former Series) 10(4): 35-41.

Sanjek, R. (2004) Going Public: Responsibilities and Strategies in the Aftermath of Ethnography, Human Organization 63(4): 444-456.

Schultze, U. (2000) A Confessional Account of an Ethnography about Knowledge Work, MIS Quarterly 24(1): 3-41.

Sein, M.K., Henfridsson, O., Purao, S., Rossi, M. and Lindgren, R. (2011) Action Design Research, MIS Quarterly 35(2): 37-56.

Simon, H.A. (1996) The Sciences of the Artificial, 3rd ed, Cambridge, Mass.: MIT Press. Squires, S. and Byrne, B. (2002) Creating Breakthrough ideas: the collaboration of anthropologists and designers in the product development industry, Westport Conn: Bergin \& Garvey, pp. 147-159.

Star, S.L. (1995) Cultures of Computing, Oxford: Blackwell.

Starkey, K., Hatchuel, A. and Tempest, S. (2009) Management Research and the New Logics of Discovery and Engagement, Journal of Management Studies 46(3): 547-558.

Suchman, L. (1987) Plans and Situated Actions: The Problem of Human-Machine Communication, Cambridge: Cambridge University Press.

Susman, G. and Evered, R. (1978) An Assessment of The Scientific Merits of Action Research, Administrative Science Quarterly 23(4): 582-603.

Thomas, M. (2003) Designers ' Dilemmas: The Tripartheid Responsibility of the Instructional Designer, TechTrends 47(34-39.

Thorpe, R. and Rawlinson, R. (2014) Engaging with engagement: how UK business schools could meet the innovation challenge, The Journal of Management Development 33(5): 470-486.

Trauth, E.M. (2000) The Culture of an Information Economy: Influences and Impacts in the Republic of Ireland, Dordrecht, The Netherlands: Kluwer Academic Publishers. 
Tromp, N. and Hekkert, P. (2013) Designing Behaviour, in: Gunn, W., Donovan, J. (Eds.), Design and Anthropology, Burlington, Vt.: Ashgate, pp. 193-206.

Vaishnavi, V.K. and Kuechler, W. (2007) Design Science Research Methods and Patterns: Innovating Information and Communication Technology, New York: Auerbach Publications.

Van de Ven, A.H. (2007) Engaged Scholarship: A Guide for Organizational and Social Research, Oxford: Oxford University Press.

Wakkary, R. (2005) Framing complexity, design and experience: A reflective analysis, Digital Creativity 16(2): 65-78.

Walls, J.G., Widmeyer, G.R. and El Sawy, O.A. (1992) Building an information system design theory for vigilant EIS, Information Systems Research 3(1): 36-59.

Wasson, C. (2000) Ethnography in the Field of Design, Human Organization 59(4): 377-388.

Wasson, C. (2002) Collaborative work: Integrating the roles of ethnographers and designers, in: Squires, S., Byrne, B. (Eds.), Creating Breakthrough ideas: the collaboration of anthropologists and designers in the product development industry, Westport Conn: Bergin \& Garvey, pp. 71-90.

Whyte, W.F., Greenwood, D.J. and Lazes, P. (1991) Participatory Action Research: Through Practice to Science in Social Research, in: Whyte, W.F. (Ed.), Participatory Action Research, Newbury Park: Sage, pp. 19-55.

Wynn, E. (1991) Taking Practice Seriously, in: Greenbaum, J., Kyng, M. (Eds.), Design at Work, New Jersey: Lawrence Erlbaum.

Zuboff, S. (1988) In the Age of the Smart Machine, New York: Basic Books. 


\section{Appendix 1. Tools for Design Ethnography}

\begin{tabular}{|c|c|}
\hline Tool & Description \\
\hline \multicolumn{2}{|l|}{$\begin{array}{l}\text { Ethnographic } \\
\text { toolkit (E4D) }\end{array}$} \\
\hline Interviews & $\begin{array}{l}\text { Interviews are a data gathering technique for obtaining rich data from people. } \\
\text { The primary purpose is for the interviewee to describe their world in their } \\
\text { words. Interviews can be structured, semi-structured or unstructured. } \\
\text { Structured interviews have a pre-prepared script, whereas unstructured } \\
\text { interviews do not and there is a need for improvisation (Myers and Newman, } \\
\text { 2007). }\end{array}$ \\
\hline Fieldwork & $\begin{array}{l}\text { Fieldwork or participant observation is a way of gathering qualitative data } \\
\text { about the people by interacting with them and observing them in their 'natural' } \\
\text { setting. }\end{array}$ \\
\hline Immersion & $\begin{array}{l}\text { Immersion is part of the experience of doing fieldwork, where the } \\
\text { ethnographer seeks to immerse themselves in the life of the people they are } \\
\text { studying. }\end{array}$ \\
\hline $\begin{array}{l}\text { Conversation } \\
\text { analysis }\end{array}$ & $\begin{array}{l}\text { Conversation analysis focuses on talk, on what people say when interacting in a } \\
\text { social situation. The primary purpose is to discover the meaning of the } \\
\text { conversation and to shed light on the underlying cultural context. }\end{array}$ \\
\hline Genealogies & $\begin{array}{l}\text { Traditionally in anthropology, genealogies were a way of finding out about } \\
\text { social practices (e.g. rules concerning marriage), social structure (e.g. kinship) } \\
\text { and the economy (e.g. the history of land ownership). Nowadays genealogy is } \\
\text { often used metaphorically to refer to the history and background of the } \\
\text { subject. }\end{array}$ \\
\hline Social mapping & $\begin{array}{l}\text { Social mapping is a way of mapping the dimensions of an individual or } \\
\text { community in order to understand the relationships within a social network. }\end{array}$ \\
\hline Demography & Demography looks at the size, composition and distribution of a population. \\
\hline $\begin{array}{l}\text { Photography, film } \\
\text { making and } \\
\text { videos }\end{array}$ & $\begin{array}{l}\text { Photography, film making and videos are used to document the daily life of the } \\
\text { people and community being studied. They can be seen as an objective visual } \\
\text { record of the research site or subjectively as a visual diary of one's own } \\
\text { fieldwork experience (Myers, 2013). }\end{array}$ \\
\hline Archival research & $\begin{array}{l}\text { Archival research is used to obtain historical documents that cannot be found } \\
\text { in any other way. Many documents in archives have not yet been digitized. }\end{array}$ \\
\hline \multicolumn{2}{|l|}{$\begin{array}{l}\text { Ethnography to } \\
\text { design toolkit } \\
\text { (E2D). }\end{array}$} \\
\hline Design workshops & $\begin{array}{l}\text { Design workshops are creative sessions in which the participants (users and } \\
\text { designers) engage in various design activities such as expressing their thoughts } \\
\text { or feelings about a new process or artifact (Emery and Devane, 2007a). }\end{array}$ \\
\hline Think aloud & $\begin{array}{l}\text { The "Think aloud" method requires designers to describe what they are doing } \\
\text { as they design and to immediately reflect on what they have done. The }\end{array}$ \\
\hline
\end{tabular}




\begin{tabular}{|l|l|}
\hline designing & $\begin{array}{l}\text { purpose of this method is to provide insights into the creative process of design } \\
\text { (Eaglestone et al., 2007). }\end{array}$ \\
\hline Designer diaries & $\begin{array}{l}\text { Designer diaries can be useful to document the process of design over a period } \\
\text { of time (Naur, 1983). }\end{array}$ \\
\hline Design thinking & $\begin{array}{l}\text { Design thinking is a systematic way of thinking and acting creatively in order to } \\
\text { understand and solve user requirements in a technologically feasible way } \\
\text { (Lugmayr et al., 2014). }\end{array}$ \\
\hline $\begin{array}{l}\text { Search } \\
\text { conferences }\end{array}$ & $\begin{array}{l}\text { Search conferences are where are group of people meet to identify issues } \\
\text { important to the group but also inspire them to action (Emery and Devane, } \\
\text { 2007b). }\end{array}$ \\
\hline $\begin{array}{l}\text { Design } \\
\text { ethnography } \\
\text { toolkit (DE). }\end{array}$ & $\begin{array}{l}\text { Co-planning and co-designing involves the designers and users working } \\
\text { together in design. }\end{array}$ \\
\hline $\begin{array}{l}\text { Co-planning and } \\
\text { co-designing }\end{array}$ & $\begin{array}{l}\text { Perceptual synthesis involves the use of visual, embodied and non-textual } \\
\text { means (e.g. pictures) in a group. Insights from each person's perceptual } \\
\text { observations are combined and used to generate themes in a group (Kilbourn, } \\
\text { 2013). }\end{array}$ \\
\hline $\begin{array}{l}\text { Perceptual } \\
\text { synthesis }\end{array}$ & $\begin{array}{l}\text { Experience juxtaposing involves exploring potential future experiences and } \\
\text { comparing these with present day experiences (Kilbourn, 2013), e.g. imagining } \\
\text { how a new product might improve one's health. }\end{array}$ \\
\hline $\begin{array}{l}\text { Potential } \\
\text { relationing } \\
\text { then exploring how people wish them to change. Drama and acting are useful } \\
\text { ways to explore the social embeddedness of possible future practices (Kilbourn, } \\
\text { juxtaposing }\end{array}$ \\
\hline $\begin{array}{l}\text { Experience } \\
\text { jotential relationing involves exposing current practices and relationships and }\end{array}$ \\
\hline
\end{tabular}

